\title{
Behavioural Economic Tools as a Way to Increase Customers' Response in the Banking Sector
}

\section{Yanko Yankov*}

\section{Abstract}

The proper functioning of the banking sector is of great importance to the national and world economy. Ever since the crisis of 2008 banks have experienced a decrease in revenue for various reasons. This decline is worrying and while external factors cannot be altered by financial institutions, their effect can be reduced with the formulation and application of a focused marketing strategy.

The purpose of this article is to determine whether implementation of behavioural finance can attract customers and improve sales in a sector with seemingly decreasing potential and growing competition.

The research topic is the change in customer behaviour as a result of implementing behavioural techniques (nudges).

The object of analysis is a leading bank in Bulgaria and its interaction with the customers.

There are three main tasks in this article:

- to show how the economic crisis as an external factor has contributed to changes in regulation and consolidation on the Bulgarian banking market;

- to conduct a literature overview of some of the behavioural economics aspects, which can be incorporated in banking practices;
- to present the results of a Bulgarian bank, which manages to improve the outcome of its campaigns and to apply the idea behind the customer decisionmaking matrix in its marketing mix by employing the tools defined in the literature overview.

There is an abundance of theoretical research on behavioural economics, far less evidence from empirical studies in various sectors and none from the banking sector. The aim of this article is to shed some light on the topic. The major assumption held in this study is that the use of behavioural finance tools in banks' marketing policies can increase customer response rate and help increase sales.

Keywords: behavioural economics; banking sector; nudges.

JEL: D04

\section{Introduction}

For the past decade the profit and stability of financial institutions has been steadily declining and only recently part of them have managed to emerge from this downtrend, cut down losses and return to their pre-crisis levels (Gutlederer, 2018). However this recovery may be short-lived as macroeconomic factors that determine the economy call for actions to be taken both internally, by the financial 


\section{Articles}

institutions themselves, and externally by the regulators. This is true for all organizations.

\subsection{Macroeconomic factors}

The business cycle is a fundamental concept in macroeconomics. It is characterised by periods of expansion and periods of recession along the longterm growth level of GDP (Madhani, 2010). Recessions are mainly characterized by a fall in production and consumption, which results in increased unemployment rate and fall in real estate prices. There are many elements that prompt negative movements in the economy; however, inflation is the main one. The higher the inflation rate, the fewer goods and services that can be purchased with a fixed amount of currency. When a recession deepens, it becomes an economic crisis (depression). The world has witnessed a number of crises that have had serious long-term consequences, such as the Great Depression in 1929 - 1933, which according to C. Romer has had a huge impact on the United States economy with a decline in GNP by $35 \%$, fall in employment rate by $25 \%$ along with all respective consequences, which returned to their pre-crisis level around 1942 (Romer, 1992); "The Nixon shock" of 1971 that suspended the convertibility of the Dollar to Gold, breaking up the Bretton Woods system and giving birth to the Floating exchange rate system causing serious destabilisation in currencies, a drop in the dollar by a third of its value with actual aftermath being reassessed even today; Japan's "Lost Decade" (1991 2000) caused by intense high-risk lending which led to a real estate price bubble that ended bursting in the early 1992 and resulted in a period of stagnation with minimal growth in GDP between 1991 and 2003. World economies are still recovering from the last "Global Financial Crisis" of 2007-2008.
Behavioural Economic Tools as a Way to Increase

Customers' Response in the Banking Sector

\subsection{Other external factors}

\subsubsection{Regulations}

While we cannot prevent recessions, as they are a part of the natural business cycle, we can predict them with a high level of certainty, which would make possible the early implementation of correcting measures in order to prevent the deepening of the recession and a possible depression. This is also one of the main responsibilities of Central Banks, whose functions are of the utmost importance with regard to the economic and financial stability of a country, including the monetary policy in the economy. This function determines the monetary policy of the state (whether it will be expansive or restrictive), which in turn affects the business cycle and determines its future development. It is important to note that the measures must be corrective and guiding, as neither a major recession nor a rapid expansion is healthy for the state's financial stability. It is necessary to take measures in the long term rather than constantly solve arising short-term problems. This is not easily feasible, given the many other factors that influence the economy which have to be taken into account when determining the monetary policy of the state. The printing of money to stimulate the economy is almost a desperate measure and should be used with great caution. As Moid Ahmad and Hetti Premaratne point out, a country may decide to implement a low interest rate policy in order to promote economic growth. Reduced profit from interest rates will cause banks, pension funds and financial institutions to redefine their strategy for cost cutting and making services more expensive, ultimately leading to low interest rate and no significant change in economic growth (Ahmad \& Premaratne, 2018). Now the EU economy is facing stagnation and reference rates cannot be reduced any further. The record low 


\section{Articles}

interest rates push investors to take on new and risky ventures for which there may be lack of demand. This aggressive expansion will lead the economy to disequilibrium, which could develop into a new crisis. Central Banks are already running out of options to stimulate growth and further deepening of the issue seems very real. Another important task of the Central Bank is banking supervision, which is of great importance for the economic development of each country. Over the last 10 years, the years after the crisis, the banking and financial sector have seen strong tightening measures and directives. In most cases - rightly so, but regulations have a strong impact on financial institutions. Among the most significant ones are:

1. BASEL II and III (International regulatory framework for banks) - an overall increase in credit costs making it more expensive to lend, without the possibility to increase interest rates due to rise in competition;

2. GDPR (General Data Protection Regulation) - generally associated with huge implementation costs and reduction in the scope of marketing campaigns;

3. MIFID II (Markets in Financial Instruments Directive) - significant implementation costs, reduction in sales due to additional qualification requirements, complication of product and/or provided information.

4. PSD 2 (Payment Service Directive) - will open the market to FinTech competitors, which will decrease banking power and profits.

5. IFRS 9 (International Financial Reporting Standards) - will lead to a dramatic increase in provisioning and substantial compliance costs

I need to make it clear that I am emphasizing on the negative effects that these regulations have on the financial and banking sector in order to explain the need for internal re-evaluation and possible restructuring that companies will have to undertake. I am not trying to deny the necessity for their existence. As Tanushev points out, bringing the functioning of capital [and financial] markets in Bulgaria in line with the wellestablished practices of European countries will help the country's accelerated growth and contribute to equalization of economic indicators for quality of life (Tanushev, 2005). Regulations are needed in order to provide this and much more.

\subsubsection{Technological changes}

Regulations, along with the current macroeconomic environment (decreasing profits from low interest rates, increased competition, cost of labour and other factors) are not the only reason why banks are now, more than ever, looking for ways to optimize expenditure. Recent technological changes have made it expensive for banks to meet the changing requirements of the customers but not meeting them would be more expensive and would come at the cost of clients. Financial technology (FinTech) companies are increasingly joining the financial/banking sector increasing the competition for clients even more. Providing services like online and mobile banking, different payment options such as credit and debit cards, nearfield communication and location services, and online Al advisors is almost mandatory nowadays. With the introduction of peer to peer lending ${ }^{1}$, big data analytics, blockchain technology and soon Nanotechnology ${ }^{2}$, the financial and banking sector is looking towards many changes. Their effect can only be

\footnotetext{
${ }^{1}$ Peer to peer (or P2P) lending aims at directly connecting lenders to borrowers while cutting the intermediary - banks and other financial institutions.

${ }^{2}$ Blockchain and Nanotechnology will change the banking and financial sector. They will provide for faster and more secure financial transactions, decentralise services and opening a possibility for new products
} 


\section{Articles}

partly estimated at this point, but nonetheless companies should make every effort to try and foresee these trends. Falling behind, digitally, will result in the company remaining a 'follower' in the market - a position from which it might not recover.

\subsubsection{Internal measures and consolidation}

In recent years, there has been saturation in the Bulgarian financial market with banks, fast loan companies and investment intermediaries.

Up until now, the significantly higher credit yields allowed these companies to operate relatively inefficiently. However, the years of high interest rates and weaker competition have passed, and banks were not prepared for the upcoming changes. The consolidations in the Bulgarian financial market are not coincidental and are the result of these changes. Postbank bought Alpha Bank, Eurobank and recently - Piraeus Bank. Cibank merged with United Bulgarian Bank, DSK bank bought Société Générale etc. There is room for further consolidation in the market. An obvious one seems to be the possible merge between Raiffeisenbank and ProCredit bank. The digital robustness of the latter will perfectly match the established market position of the former, slightly more conservative bank, while maintaining responsible and stable growth of the Austro-German roots of the two banks. Many of the consolidations have been driven by the various market changes and new regulations which put weaker performing and inefficient banks in no position to meet the necessary requirements and continue their normal functioning without merging with a well-established bank. The globalization and technological progress over the last two decades has changed the shape of the financial market. There are no consumer barriers on entry or exit, on time or location. As of March 2019, the twenty licensed banks
Behavioural Economic Tools as a Way to Increase

Customers' Response in the Banking Sector

in Bulgaria have more than 2,000 branches and business centres and are developing digital and remote platforms to provide even better coverage. Despite the strong presence of foreign banks as lon Lapteacru's findings show - they exhibit the same market power and convergence rate as the regional average (Lapteacru, 2018). This finding is important, because it means that banks in Bulgaria face the same challenges irrespective of their origination and each has an equal chance of standing out from the rest if it applies the necessary measures. If foreign institutions tended to exhibit higher convergence rate (acceptance and desirability by the clients) before 2000 this is no longer the case and we can see now that the consumer turns out to be less sensitive to country of origin and more interested in personal relationship and trust as his day becomes busier and products become more complicated.

Is there any other solution to the increasingly declining revenues? Is consolidation the only way that banks can handle the recent changes in the market and the tightening of regulations? Innovation should be one of the key priorities for every organization in the world as it will be the driving force of their success or failure. The inability to compete in the digital world will lead to the inevitable demise of the company. There are many examples in the real world, like Kodak, Motorola, Nokia, Blackberry, MySpace, Xerox, JCPenny and so on.

An organization could be offering the best product and/or service on the market and would not be able to maximise profits without a proper communication policy. Even if all necessary measures are taken, an organization will struggle to become a leader if it does not define such marketing strategies that are customer-oriented. Behavioural economics is one such field of study that can be incorporated in the marketing strategy of a 


\section{Articles}

company. It is fairly inexpensive as it does not mean change of prices, products or services sold. It means change of communication, change of presentation, change of delivery of information. The aim of behavioural economics is not to "manipulate" the customer, but rather to assist him during the decision-making process.

\section{Literature review}

In order to counteract external factors financial organizations need to reconsider their marketing mix and determine its weak spots.

In his research regarding bank marketing strategies, Arthur Meidan defines eight different strategies divided in two main categories - growth and competitive strategies and three main stages in formulating the strategy - identification of target markets and their needs; defining constraints on achieving the objective; allocating marketing resources. $\mathrm{He}$ concludes that when facing certain changes, such as increased competition, change in technology, inflation, etc., banks will have to define appropriate marketing strategies. These strategies should be based on one or more advantages currently owned. They can include - strategy for cutting costs, geographical expansion, market penetration, market-leader strategy, market follower strategy, etc. (Meidan, 1983). This paper is more than 40 years old, but it is true to this day. No company can be the leader in all aspects. It should clearly define the fields where it wants to 'lead' and those, where it will 'follow'. Kaur (2015) identifies two main groups of customers - relationship and transaction-oriented SME customers. The latter tend to be more recently established and much more sensitive to prices, while the former focus more on bank features and need accommodation. He argues that banks need to choose a different strategy for both groups.
Consumer behaviour also needs to be understood in order to choose the appropriate marketing strategy. We live in a highly digitalized world where information from one part of the planet can reach another in a matter of seconds and there is no greater advantage than high customer satisfaction. There is a vast selection of books, research papers, academic literature and articles on consumer behaviour and even though financial goods and services tend to be slightly more complicated, the decision-making process remains the same. Because of that, the relationship in the financial sector, between the buyer and the seller, needs to be built on trust and transparency. In their research $\mathrm{B}$. Howcroft, P. Hewer and R. Hamilton find that consumers tend to stay with the same current account provider for a long period of time due to inertia, rather than loyalty. They show that consumer propensity to switch between providers increases, when confidence levels are relatively high and tangible benefits can be identified. And that current account providers must actively adopt consumeroriented strategies which actively promote retention and loyalty (Howcroft, Hewer, \& Hamilton, 2010).

As customer satisfaction and customer loyalty are becoming more and more vital to the company's growth, many economists, psychologists and experts from different fields are increasingly investing more of their time in defining and explaining the effect of behavioural factors that affect customer decision making. When it comes to understanding consumer behaviour, Kanev and Terziev explain that most people fail to maximize expected utility; they would adhere to simplified and incorrect decisionmaking strategies, and tend to make better choices when they have a limited number of alternatives. They would act against their own interest, postponing important decisions and 


\section{Articles}

sticking to the default option, even if it is not the best choice (Kanev \& Terziev, 2017). The view that the consumer is generally ill-informed and assisting him in making the correct decision is necessary for his satisfaction is shared by other authors as well. SweeHoon Chuah and James Devlin find that the insights given by behavioural economics are useful in helping to explain various aspects of consumer behaviour in financial services markets. Understanding of the implications of behavioural economics may help in fashioning a choice architecture that is more likely to bring the desired consumer response. To present choices in a manner that maximizes take-up of products and services, encourages or engineers on-going behavioural loyalty and thereby helps to cement relationships between firms and customers (Chuah \& Devlin, 2011). Nudges, which are closely related to behavioural economics, have also received a lot of the warranted attention. In his study on how behavioural economics can shape public policies, Andrew Leigh discusses the benefits of nudges such as "framing", "loss aversion", "defaults" and other techniques like "randomization" and simplification for policymakers (Leigh, 2015). Ian McAuley argues that behavioural economics does not go against "standard economics" but rather brings more explanatory power to it and can help guide public policies in directions that require attention (McAuley, 2010). N. Jacquemet also views behavioural economics, the objective of which is to enrich and amend the theoretical approach of individual and social decisions based on psychological regularities rather than to refute the idea of "homo economicus". He argues that one should incorporate non-material motivation, cognitive shortcuts and other decision making inconsistencies in the decision-making process, as a method of understanding consumer behaviour (Jacquemet, 2017).
Behavioural Economic Tools as a Way to Increase

Customers' Response in the Banking Sector

Disproving the standard economic theory is not the goal of behavioural economics. And while the benefits are obvious from the many examples and best practices, it is rarely applied - especially in the financial sector.

According to Ariel Cecchi, nudges are a powerful tool that intends to trigger a favourable decision that in order to be fully effective has to reinforce positive behaviour. $\mathrm{He}$ concludes that their design needs to be carefully tested and combined with transparent and clear financial products and services (Cecchi, 2018).

Uber partnered up with Express POOL to identify three important to the customer concepts, such as idleness aversion, operational transparency, and the goal gradient effect, when presenting the "wait time". By applying behavioural economics, they observed 11-percent reduction in the post-request cancellation rate (Kamat \& Hogan, 2019).

Amy Brown shows the exact power of the "default" option (switching from opt-in to optout) for a 401 (k) insurance plan in a large company increased participation of new employees from $37 \%$ to $86 \%$ and among the lowest-income employees from $13 \%$ to $80 \%$ (Brown, 2010).

I have investigated over 100 books, articles, research papers, dissertations, etc. in English, French, Spanish, German and Bulgarian and I could not find any which provide empirical data regarding results from behavioural finance in the banking sector in Bulgaria or around the world. This does not mean that banks do not use nudges. "Strands" is a company with expertise in the field of big data, Al and Machine learning that work with top-tier financial institutions. Together with Jeff Kreisler they investigate the role of behavioural science and how banks and financial institutions can benefit from it. In their eBook Behavioural Economics - The 


\section{Articles}

bank's secret weapon, they define 10 main biases in the banking sector - opportunity cost; anchoring; loss aversion; the power of language; confirmation bias; sun cost; mental accounting; the pain of paying; the power of free and self-control. BBVA (Banco Bilbao Vizcaya Argentaria) is applying behavioural economics to portfolio construction. Barclays focuses behavioural economics in investment decision making. Bank of America has a behavioural finance team. Merrill Lynch also has a behavioural finance team of 25 members. PNC Financial Services cooperated with IDEO to find new ways of attracting millennials through behavioural techniques, etc. (Kreisler, Ballesteros, Crean, \& Pakulyte, 2018). Some banks do not even realise they are using them.

It appears that these principles are being applied across different regions, countries and continents. There also seems to be a lack of empirical evidence supporting the results of such experiments in the banking sector. This is why this paper will provide just that.

\section{Marketing mix}

The marketing mix, as a term, was introduced in 1964 by Neil Borden (Professor in University of Harvard) to designate the combination of specific measures and actions aimed at directing the consumer's attention to the goods and services of the firm carrying out those activities. The traditional marketing mix, which is not very different within the banking sector, also includes product, price, distribution and promotion (Borden, 1964). This model has been developed further by (Booms \& Bitner, 1981), which add "people", "physical evidence" and "processes" into the mix. The marketing mix plays a vital role in determining the strengths and weaknesses of a company and its relative standing amongst competitors. Because of changes in the technological world, digitalisation and globalisation, the banks have been forced to further improve their marketing mix. Location and time is becoming less and less of an issue with the increased provision of online services such as mobile and internet banking, 24/7 call centre services, etc. Increased competition in the financial sector leads to lower fees and interest rates which forces banks to search for profit-making alternatives. In Bulgaria, loans are currently provided at historically low interest rate levels and the losses from one non-performing loan can easily exceed the profitability of many performing loans. This is why banks should be heavily relying on the previously mentioned upsell and cross-sell as one of their main marketing strategies. Changes in the macroeconomic environment are very probable and banks should consider them, when defining their credit policy. For example, high interest rates decrease investment and borrowing rate, but the borrower should still maintain a sensible credit risk policy. Lending 100000 at a 10-percent interest rate does not outweigh the benefits of lending 100000 at a 2-percent interest rate if the former loan is non-performing. Of course this means losing the occasional customer that opts for a revolving loan for his investment needs. Banks will then need to rely on crosssell in order to compensate for decreasing revenue from lending products and increased levels of competition. But most leading banks already provide their customers with various products such as insurances, Credit cards, POS terminals, pension funds, and investment funds and so on. So what would differentiate one bank from the other? Superior customer understanding, which lies in the development of three main pillars:

a) FinTech - an integral part of the marketing mix (process and product).

b) Social responsibility - an integral part of the marketing mix (people and public relations). 


\section{Articles}

c) Behavioural economics - an integral part of the marketing mix (promotion).

And this can already be seen. With the adoption of the Payment Service Directive (PSD2), for example, banks are already either partnering up with FinTech companies (like IDnow and Commerzbank) or trying to develop their own innovative platforms in order to keep up with the changes in the digital world. Financial institutions are also focusing a lot on their employer's brand and their public image by sponsoring different kinds of events in order to get higher recognition. A lot has been written but not much has been done for proper application of behavioural economics. This idea is still very new and unexplored in Bulgaria. But before we explore it further, it would be best if we take a quick look at consumer behaviour.

\section{Consumer behaviour and decision- making matrix}

In order to explain how behavioural economics works, we must take a look at what defines consumer behaviour and consumer rationality. The latter, also known as economic rationality is the assumption in demand theory that the consumer will optimize their expenditure in order to gain maximum value. I will not go into details on why this theory is inherently flawed, but I will leave you with the picture of thousands of people waiting in line for hours for the new iPhone, because the one from last year "has" to go. Before I am accused of promoting Apple, I need to clarify that this behaviour is of course valid for all brands of smartphones and "vanity" products. So the economic theory is based on the fact that consumers make rational and informed decisions when making a purchase, however the behavioural economic theory suggests that people can be very irrational and their decisions are often based on emotional factors and are generally ill-informed. I am
Behavioural Economic Tools as a Way to Increase

Customers' Response in the Banking Sector

not trying to defy the fact that consumers can be rational, I am merely suggesting they are also very emotional.

It is clear that no company can operate without customers, at least not for long, and in order for a business to be successful it has to be able to identify and understand these customers so as to promote steady growth and loyalty. This task includes at least two actions: the consumer behaviour has to be measured and then explained. Without that the success of a business would be based on luck rather than anything else. The measurement of consumer behaviour consists of giving answers to the following questions: who are the targeted customers, what do they buy, how do they buy, where do they buy, when do the buy, how do they form their choice and so on. Decades ago the answer to these questions might have been provided ad hoc, spontaneously, due to the closer relationship between the "producercustomer". The consumer buys product from the local farm and can then provide instant feedback on the quality of service and goods. Following the mass production and technological revolution this relationship has been mediated with some of the distribution channels being "producer - whole seller - retail seller - agents - customers". While they do work, the producer has to count on agents and retail sellers in order to receive feedback on the customer's wants and needs. The standard purchase process consists of the following phases - 1) The consumer becomes aware (or is made aware) of his needs; 2) He acquires additional information; 3) $\mathrm{He}$ evaluates the alternatives; 4) $\mathrm{He}$ decides on the purchase of the service/good; and economists have defined a fifth phase, which includes the customer's behaviour after purchase. This fifth phase is very important because customer satisfaction is one of the most important factors in 


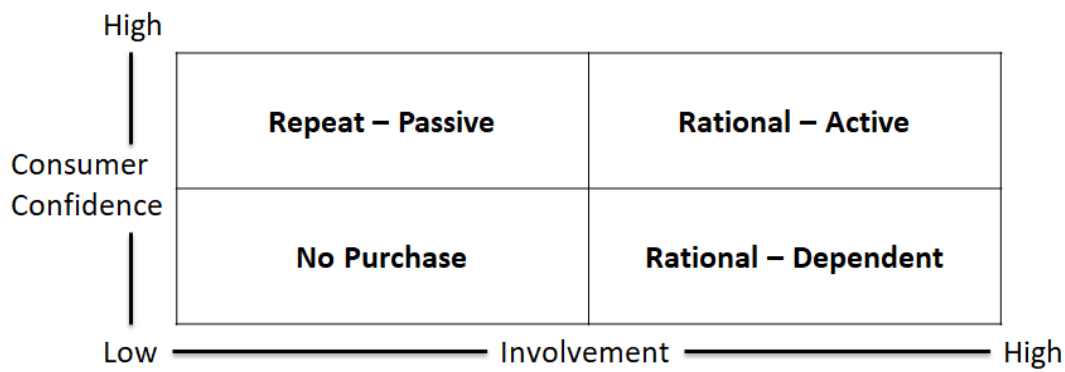

Figure 1. Consumer behaviour matrix

creating a successful business. But how is the consumer behaviour formed? Antony Beckett, Paul Hewer and Barry Howcroft conclude that involvement and uncertainty create the following consumer behaviour matrix (2000):

Paying bills online for example, would qualify as a repetitive task that you do not put much thought in, in other words, there is low involvement and the consumer is highly confident that he will get the steps right. Generally speaking, if the level of involvement is low, the purchase does not represent a difficult decision and/or the customer does not perceive real benefits from the purchase. If consumer confidence is low he cannot properly assess whether the purchase is a good idea or not, therefore the risk is too high. A good example of a rational-dependent purchase would be the purchase of company shares. Most of us tend to have a very limited knowledge regarding company shares and we usually rely on the expertise of other people. Purchasing shares can be quite expensive and it is hardly similar to getting a bad haircut and while the level of involvement has to be high, the consumer confidence is usually low. This is why most of these purchases are "dependent". We depend on someone else's expertise in order to make a rational decision based on actual facts, not on the belief that we will get it right. For most customers in the banking/financial sector, decisions for the purchase would fall in the "Rational Dependent" category. With the help of European regulations that promote financial control and incentivise higher transparency, the European Union is trying to improve consumer confidence and push the decisionmaking process in the "Rational - Active" group. This would not only allow for better decision making on the customer's side, but will also improve confidence in the market, increase demand and promote economic growth. Nevertheless, there is always the possibility that there is no actual purchase, due to lack of confidence or trust.

\section{Behavioural economics}

Behaviourism was founded by John B. Watson, an American psychologist who established the psychological school of behaviourism in 1913 and ever since, it has been receiving more and more attention. With the globalisation and technological advancement in the past two decades, it feels as it is increasing exponentially. The field of economics has always been intertwined with other fields of study so it is not surprising that it would benefit from behaviourism as well in order to give birth to behavioural economics. This notion is still very new in Bulgaria, but of course we have all applied behaviourist approaches at some point in our lives, most of the times even without realising it. Put simply, behavioural economics is a field that 


\section{Articles}

focuses on consumer limitations such as time and information constraints. It attempts to provide the client with a solution by applying behavioural "nudges" in a way that helps him feel in control when making decisions. I would like to start off by saying that, in the short run, you could manipulate a person into accepting something, which is not good for him, but in the long run he would know he has been manipulated. This will never create a healthy relationship and would never lead to customer loyalty.

\subsection{Key concepts in behavioural economics}

When it comes to behavioural economics there are a lot of concepts, biases and nudges that one could use and apply. In order to provide a clearer understanding, I would like to introduce some of the main ideas, before going into detail of the empirical work:

a) Predictably irrational behaviour - Many of our decisions and choices reflect mistakes in logic and could be described as irrational. It can be argued that they are made repeatedly in a systematic and predictable way;

b) Heuristics and biases - heuristics represent cognitive short-cuts, rules of thumb and biases represent a systematic "error" in thinking and behaviour;

c) Choice architecture - recognises that the way a choice is presented influences the decision-maker. Choice architecture describes the tools available for influencing behaviour, without removing or forbidding any options or changing their incentive;

d) Nudge - a stimulus that would alter a person's choice in a predictable way. A common example of a "nudge" would be putting small and cheap articles (usually sweets) next to the checkout point in stores;

e) Choice overload - the concept that
Behavioural Economic Tools as a Way to Increase

Customers' Response in the Banking Sector

too many available choices will lead to uncertainty and ultimately to a nopurchase decision;

f) Loss aversion - the idea that the pain of losing something you own is much stronger than this of gaining something that you do not;

g) Endowment effect - following "loss aversion", the idea is that a person values something they possess more than something that they do not;

h) Present bias - the idea is that people value gains in the present more than they value gains in the future. This is one of the reasons why most of us prefer to slack off and have fun to benefit from short-term gains, rather than to work hard to achieve a long-term goal, which would be more valuable (like learning a language);

i) Social proofing - people are social animals and we like to be identified as part of one or more social groups. As we try to identify ourselves with a preferred group, we make decisions based on the idea of belonging to that group;

j) Personalisation - everyone wants and thinks they deserve "special" attention. Nobody wants to be put in a common denominator and generally feels better and is prone to reciprocate when he receives personal attention;

k) Scarcity - the idea that when there is too few of a good or service, it must be expensive and very valuable. Simply put, humans place a higher value on an object that is scarce, and a lower value on those that are in abundance. For example, diamonds are more valuable than rocks because diamonds are not as abundant. (Mittone \& Savadori, 2009).

But what can be achieved by intentionally applying various behavioural nudges in the communication with the clients? If we take a look at what one of the banks on the Bulgarian market has implemented, we can do just that. 


\subsection{The campaign}

In Sofia, Bulgaria, one of the leading banks on the market decided to partner up with an Australian company specialised in behavioural economics in order to see the effect on its lending and non-lending products. The bank runs promotional campaigns on a monthly basis, but decided to try two special campaigns, one for lending products (unsecured loans) and one for nonlending products (package programs). Both campaigns, lasting almost 45 days, ran in 2019 from beginning of June to mid-July. The two campaigns ran simultaneously, but targeted two different customer segments; one was suitable for lending and the other - not so much. The customer base of eight branches was divided into a "test group" and a "control group". These groups would then be split between the lending and nonlending campaign and were contacted by the branch, by a call centre agent and received an offer via online banking. The control group were treated as usual with no changes in the communication - the specialists in the branches had no instruction on what to say, the offer in the online banking was unchanged and the call centre used an old call script that did not include behavioural nudges. This control group is very important as it serves as a reference point to track the actual effect of the nudges. The test group however was contacted by the same channels, all of which were instructed to introduce specific behavioural nudges into their communication with the clients. Groups were not informed of any testing nor were changes made to the products. They were the same products, at the same price, just offered in a different way. As behavioural economics is based on many concepts, biases and ideas, some of which presented above, the team was aware that these campaigns might be unsuccessful as it is hard to evaluate which ones will have impact on the customer and which ones will not. The test was going to be deemed successful at 30-percent increase in customers' interest. In order to keep things simpler, I will divide the next part into "lending" and "non-lending" campaign.

\subsection{Lending campaign}

Lending products are products with higher involvement as they are a bit more complicated to fully understand. Apart from the type of product offered, the channel is also very important. There are three main sales/ communication channels with the customers call centre, online banking and branches. There is also mail and communication platforms such as Viber, Facebook, Instagram, etc., but for now, let us focus on the first few.

\subsubsection{Call centre}

Banks rely heavily on their call centre so naturally. Two call centre agents contacted control group clients using the old script and two of them contacted test group clients using the new script. The old call script would look like this: 
$\mathrm{Hi}, \mathrm{I}$ 'm calling from ............., my name is .......

Could I speak with the manager of .................. LTD,

- If manager not available: Find a better time, and the name of the manager.

Generic and

irritating

- If wrong number: Choose result "Wrong number"

- If yes, continue:

$\mathrm{Mr} / \mathrm{Ms}$....... Is this a good time to talk?

- $\quad$ if No, ask for a suitable time to contact him/her again

Assumes 3

negativity not

possibility

I would like to thank you for being a cystomer of .... And as our special customer we have a special offer for you. In case you need 3 additional funding for your business, we can offer you an unsecured loan at preferential rates $1 \mathrm{M}$ Base $+6,4$ without paying application fee. As a BONUS we can offer additional funds with the International Credit card, 5 also without application fee, as well as a package program, 5 with which you can reduce your everyday banking fees at $10 \%$ discount for the first year. You can also get preferential rates for a lease. 5 This offer is valid until the end of February 2019. Does this sound interesting?

- $\quad$ if No, continue: Thank you for your time, $\mathrm{Mr} / \mathrm{Ms} 6$ ! I have marked in our system that you are not interest in the offer. In case you change your mind, you can always contact the nearest branch. I wish you a good day!

if Yes, Inform the servicing branch to contact the customer

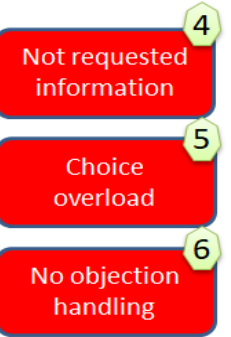

Figure 2. Old unsecured loan call script ${ }^{3}$

The bank firstly omitted the polite question "is this a good time to talk" ("1"). This was removed because it is believed that if it is not a good time, the person would say so. Asking him only helps him to adhere to the "Default" (concept of behavioural economics - people dislike taking action). Emphasizing one option as the default choice will encourage people to strongly choose that option over others; in this case - not to talk. This is followed by the standard appreciation of the person being a customer ("2"). Customers are well aware that they are valuable. Repeating it does not make it truer and irritates most of them as it is considered a generalization. The sentence "in case you need" ("3") was removed because it assumes negativity, which is something we should all avoid in our conversation. The information regarding the interest rate ("4") was not only unwanted at this time, but also makes the conversation even longer. It has now turned into a monologue and the customer is probably already not listening. Number "5" leads back to the "choice overload" mentioned earlier - The bank is now throwing products at the customer and the latter is now clueless to what the former is actually calling about. Even if he is interested in all of these products, there is now almost no way he can make a correct decision over the phone. The last thing that had to be changed was objection handling ("6"). This absolutely does not mean attacking the customer with questions such as "why are you not interested?", but rather going into a much more preferred direction -"I understand. Would it be possible that you provide me with information on what you would be interested in the future or how could we make our offer more suitable for you?"

It is possible to argue that these are not actually mistakes. Some people might even prefer it to a different setting, but for the purpose of the experiment, it was considered that they have a negative impact on the listener.

Before I present the changes made, I cannot stress enough that these techniques should not be used for misconduct and

\footnotetext{
${ }^{3}$ Text provided by the Bulgarian bank
} 


\section{Articles}

bad practices. Their idea is not to force the customers into making any decision that he is not comfortable with. The information they provide should be 100-percent accurate and based on actual data. It is not correct to say "most of our clients" do this, if it is not true. Unfortunately, violations of standard communication norms can occur wherever humans are involved.

After some alterations, the call script looked like this:

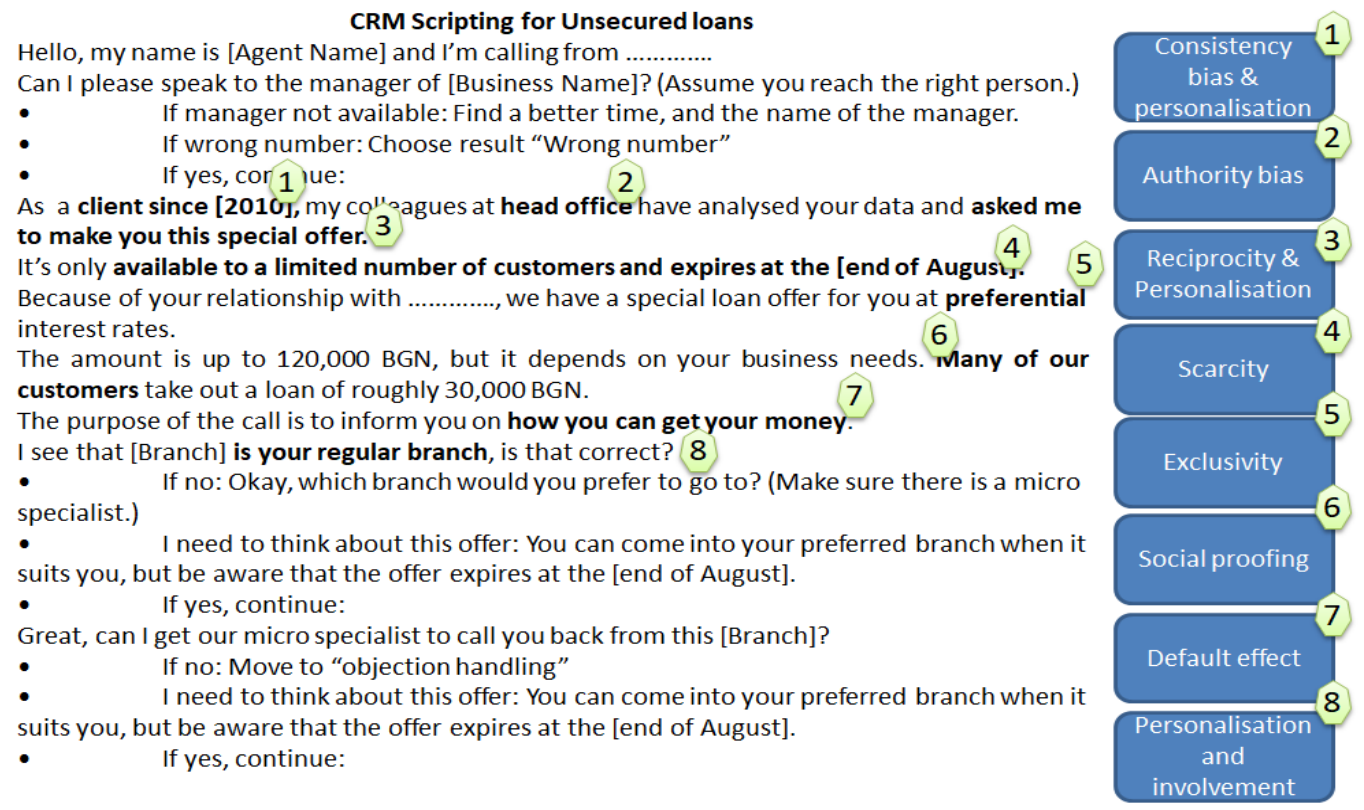

Figure 3 - New unsecured loan call script ${ }^{4}$

Even at a quick glance, this call script already looks better than the old one. "1" is the consistency bias, which is effective because people are driven to be consistent in all areas of their life. Pointing out this consistency more or less encourages it even more. The clarification of the year is a personalized touch that increases the effect of the consistency bias. Number "2" represents an authority bias - the customer is now aware that a more important figure is involved and becomes more intrigued. Following is the third bias - Reciprocity ("3"). People have a natural tendency to seek equality which leads them to reciprocate efforts and gifts they receive, which makes them much more likely to listen.
Then comes scarcity ("4") - setting a deadline for the offer makes the client less inclined to postpone decision making. "5" represents the exclusivity bias and increases attention. There is some sort of a special offer, but what is it? Not mentioning it immediately helps the customer stay present for the remainder of the call because, if mentioned earlier, he would not be able to concentrate on anything that follows. Social proofing is a very strong nudge and it comes next ("6"), now the customer is aware that many of the other clients take a loan of roughly $30,000 \mathrm{BGN}$. The inclusion of the amount also serves as an "anchor" - a bias that helps an individual to make a decision based on an offered piece of information. The

\footnotetext{
${ }^{4}$ Text provided by the Bulgarian bank
} 


\section{Articles}

sentence "How can you get your money" ("7") is not only based on the default effect but also on the endowment effect. The default is that the customer is interested in taking the loan; the endowment effect is that money is already his for taking. This could also be related to "priming" a technique that prepares someone for action. The last nudge ("8") has been added in order to make the client the active party in the conversation and to confirm subsequent steps.

It would be difficult to assess which changes have had stronger impact on the customer's decision when so much has been changed, however the call centre called 496 companies from the control group and $\mathbf{5 2 1}$ from the test groups and the results were more than clear:

Table 1. Call centre results for loan campaign ${ }^{5}$

\begin{tabular}{|c|c|c|c|c|}
\hline 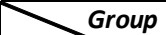 & \multicolumn{2}{|c|}{ Control } & \multicolumn{2}{|c|}{ Test } \\
\hline Resi & Number & Percentage & Number & Percentage \\
\hline Interested & 40 & $8.06 \%$ & 79 & $15.16 \%$ \\
\hline Informed & 235 & $47.38 \%$ & 200 & $38.39 \%$ \\
\hline Not interested & 130 & $26.21 \%$ & 105 & $20.15 \%$ \\
\hline Other & 91 & $18.35 \%$ & 137 & $26.30 \%$ \\
\hline Grand Total & 496 & $100.00 \%$ & 521 & $100.00 \%$ \\
\hline
\end{tabular}

The "interested" customers from the test group are twice as more. And clients that would usually state they are not interested or just "informed" felt inclined to provide reasoning for their refusal and would fall in the category "Other". Category "Other" comprises of all customers that: a) did not answer their phones; b) answered but said that it was not a good time to talk; c) did not want to say they were not interested so they provided additional information to why they are interested, but now it is not the best time for such a decision. Their number has also increased (almost by 8 percentage points). This is owed to the reciprocity effect. This is very interesting and also the idea behind behavioural economics -
Behavioural Economic Tools as a Way to Increase Customers' Response in the Banking Sector

not to force a decision, but to get the person interested and involved.

\subsubsection{Online banking pop-ups}

Online banking is another effective channel to convey a message to the customers. Customers are sent a "pop-up" offer, which pops on their screen as soon as they log into their account. They can immediately read the offer and select one of the options "Apply now", "Interested - contact me", "Not interested". If they do not want/have the time to read through it now, they can hide the offer, putting it into archive or cancel it only for this login (meaning it would pop up again on the next login). By pressing the respective action button the bank is immediately notified of the customer's decision and can take direct action. This pop-up in the online banking was changed in a similar fashion and resembled the call script for unsecured lending. The online campaign ran under the same circumstances and in the same period, with a control and test group. The results were the following:

Table 2. Online banking results for loan campaign ${ }^{6}$

\begin{tabular}{|l|r|r|r|r|}
\hline \multirow{2}{*}{ Result } & \multicolumn{2}{|c|}{ Control } & \multicolumn{2}{c|}{ Test } \\
\cline { 2 - 5 } & Number & Percentage & Number & Percentage \\
\hline Apply now & 9 & $3.00 \%$ & 20 & $\mathbf{6 . 6 7 \%}$ \\
\cline { 2 - 5 } Interested & 8 & $2.67 \%$ & 45 & $\mathbf{1 5 . 0 0 \%}$ \\
\cline { 2 - 5 } Not interested & 75 & $25.00 \%$ & 123 & $41.00 \%$ \\
\cline { 2 - 5 } Other & 208 & $69.33 \%$ & 112 & $37.33 \%$ \\
\hline Grand Total & 300 & $100.00 \%$ & 300 & $100.00 \%$ \\
\hline
\end{tabular}

We can see even better results in the online banking campaign. Out of 300 customers in the test group and 300 in control group there is almost $63 \%$ response rate in the former as opposed to $31 \%$ response rate in latter. Not only clients were more engaged and clicked on one of the options, but immediate sales increased by more than $100 \%$ (9 against 20) while interested customers increased by more than $460 \%$ - 8 to 45 . Not interested clients

\footnotetext{
${ }^{5}$ Conducted sociological test by the Bulgarian bank and own calculations.

${ }^{6}$ Conducted sociological test by the Bulgarian bank and own calculations.
} 


\section{Articles}

have also increased, but mainly due to higher response rate. Category "Other" is comprised of all customers that did not select any of the options. This includes customers that did not log into their online banking for the duration of the campaign, but the selection included only customers that visit their online banking more often (at least 2 times per month).

\subsubsection{Branch network}

Branch network results were the same. However, because of to the personal factor, they could be viewed as slightly less accurate or skewed due to different behaviour of relationship managers, as well as possible alterations and individual sales techniques.

\subsection{Non-lending campaign}

Non-lending products have only recently become a serious topic for banks. The developments in the banking sector in Bulgaria, for the past two decades, could be broadly summarized in these four main stages:

a) Period of extensive lending growth (2000 2008); b) Non-lending period characterized by debt collection and restructuring (2008 2012); c) Restoration period and renewal of lending (2012 - 2015); d) Period of increased competition and decreasing margins (2015 now). This decrease in margins has forced banks to provide loans at historically low rates. The only way to minimize these losses is through cost optimization and cross-selling of additional non-lending products. This is why these products are very important for banks and sometimes feel like they are forcefully being pushed into the hands of the customer, occasionally even crossing the line of recommendatory into "mandatory". Since non-lending products typically exhibit a lower level of involvement ${ }^{7}$ it is interesting to see whether nudges will have the same effect. During the lending campaign, a group of 300 customers, not suitable for loans, were provided with a different offer (pop-up) in their online banking - for package programs. Out of 150 customers from both groups, the results were the following:

Table 3. Online banking results for package program campaign ${ }^{8}$

\begin{tabular}{|c|c|c|c|c|}
\hline Grou & \multicolumn{2}{|c|}{ Control } & \multicolumn{2}{|c|}{ Test } \\
\hline Resu & Number & Percentage & Number & Percentage \\
\hline Interested & 14 & $9.33 \%$ & 34 & $22.67 \%$ \\
\hline Not interested & 49 & $32.67 \%$ & 44 & $29.33 \%$ \\
\hline Other & 87 & $58.00 \%$ & 72 & $48.00 \%$ \\
\hline jrand Total & 150 & $100.00 \%$ & 150 & $100.00 \%$ \\
\hline
\end{tabular}

It is obvious that there is almost a 143-percent increase of interest. No drastic decrease in numbers of "Not interested" customers or responding customers ("Other") can be seen, but it is likely due to the smaller selection and the fact that most are already familiar with package programs and have been offered one of them at least a few times.

The sample size is not big, but coupled with the results from the lending campaign in the call centre, the branch network as well as the online banking, provides for a sound result.

\footnotetext{
${ }^{7}$ I avoid using the word "simpler" because some non-lending products, such as investment/insurance plans can appear much more complicated.

${ }^{8}$ Conducted sociological test by the Bulgarian bank and own calculations.
} 


\section{Articles}

\section{Conclusion}

Behavioural economics is not "the solution to all problems". It also has its flaws and it has been criticized. But carefully applied and incorporated within the communication policy of a company it can have a significant impact. From the presented results of the Bulgarian bank, it can be seen that there is a substantial increase in the customers' interest to the same offer that they would normally receive. A lot of clients also felt compelled not to say "no", but to provide explanation to why they are interested, but that now is not the best time and that they will contact the bank later. As I already mentioned, the idea is not to force the customer into accepting a product or service that he does not wish. The only goal should be to get the customer motivated, interested. To make him an active party in the sales process and provide him the information in a way that is easily understandable and relatable. This is how banks (and any company) can increase sales without making any changes to the products that they offer in order to mitigate negative effects of the external environment. These techniques represent a valuable part of the communication and should be applied in a scrupulous manner. What this paper successfully proves is that these nudges work and I hope it is the cause for further practical implementation in the banking sector. More tests have to be done and different nudges have to be weighed in a "controlled" environment to evaluate their benefits in order to provide for a better understanding of the customers. Some nudges will perform better than others, and for understandable reasons they have to be used very carefully. Further experiments in the field of behavioural economics need to be done and it would be very interesting to determine whether these nudges affect both male and female at the same rate. How they affect people of different culture, age and educational background. But in order for this
Behavioural Economic Tools as a Way to Increase

Customers' Response in the Banking Sector

to be possible, more companies will have to share their experiments and data.

\section{References}

Ahmad, U., \& Premaratne, H., 2018. Effect of Low and Negative Interest Rates: Evidence from Indian and Sri Lankan Economies. Business perspective and research, 6(2), pp. 90-99.

Beckett, A., Hewer, P., \& Howcroft, B., 2000. An exposition of consumer behaviour in the financial services industry. International Journal of Bank Marketing, 18 (1), pp. 15 - 26.

Booms, B., \& Bitner, M., 1981. Marketing Strategies and Organizational Structures for Service Firms. Marketing of Services, James H. Donnelly and William R. George, eds. Chicago: American Marketing Association, pp. 47-51.

Borden, N., 1964. The Concept of the Marketing Mix. Journal of Advertising Research, pp. 2 - 7.

Brown, A., 2010, March. Behavioral Economics:Applications for Financial Services. Retrieved August 15, 2019, from Federal Reserve Bank of San Francisco: https:// www.frbsf.org/community-development/files/ Behavioral_Economics_Brown.pdf

Cecchi, A. 2018, November 18. Nudges in Personal Finance: The Case of Overdrafts. Retrieved August 15, 2019, from Behavioral economics: https://www.behavioraleconomics. com/nudges-in-personal-finance-the-case-ofoverdrafts/

Chuah, S., \& Devlin, J., 2011. Behavioural economics and financial services marketing: a review. International Journal of Bank Marketing, 29 (6), pp. 456-469.

Gutlederer, C., 2018, June 20. Ten years after the onset of the financial crisis: Austrian banks are back to normal. Retrieved August 15, 2019, from Oesterreichische Nationalbank Eurosys- 


\section{Articles}

tem: https://www.oenb.at/en/Media/20180620. html

Howcroft, B., Hewer, P., \& Hamilton, R., 2010. Consumer decision-making styles and the purchase of financial services. The Service Industries Journal, 23 (3), pp. 63-81.

Jacquemet, N., 2017. Développements récents de l'économie comportementale et expérimentale: Introduction. Revue Economique, Presses de Sciences Po, 68 (5), pp. 719-725. Kamat, P., \& Hogan, C., 2019, January 28. How Uber Leverages Applied Behavioral Science at Scale. Retrieved August 15, 2019, from Uber Engineering: https://eng.uber.com/ applied-behavioral-science-at-scale/

Kanev, D., \& Terziev, V., 2017. Behavioural economics: development, condition and perspectives. SOCIOINT 2017- 4th International Conference on Education, Social Sciences and Humanities, (pp. 595 - 606). Dubai.

Kaur, M., 2015. Bank Selection Process and Market Segmentation: Evidence from Indian Exporting SMEs. Vision: The Journal of Business Perspective, 19 (2), pp. 79 - 88.

Kreisler, J., Ballesteros, M., Crean, A., \& Pakulyte, V., 2018. Behavioral Economics: The Bank's Secret Weapon. Barcelona: Strands.

Lapteacru, I., 2018. Convergence of bank competition in Central and Eastern European countries: do foreign and domestic banks go hand in hand? Post-Communist Economies, 30 (5), pp. 588-616.

Leigh, A., 2015. How behavioural economics does and can shape public policy. The Economic and Labour Relations Review, 26(2), pp. 339-346.

Madhani, P., 2010. Rebalancing Fixed and Variable Pay in a Sales Organization: A Business Cycle Perspective. Compensation \& Benefits Review 3 (42), pp.179-189.

McAuley, I., 2010, August. When does behavioural economics really matter? Australian Economic Forum, (pp. 1 - 28).

Meidan, A., 1983. Bank Marketing Strategies. International Journal of Bank Marketing, 1 (2), pp. 3 - 17.

Mittone, L., \& Savadori, L., 2009. The Scarcity Bias. Applied Psychology, 58 (3), pp. 453-468.

Romer, C. D., 1992. What Ended the Great Depression? The Journal of Economic History, 52 (4), pp. 757-784.

Tanushev, C., 2005. The capital market and economic growth acceleration (in Bulgarian). International science conference: "Marketing and strategic planning: theory, practice and training. Sofia: University publishing house. 